UNESC

\title{
Escritório Modelo Interdisciplinar (EMI): Projeto Participativo no Bairro Nova York - Forquilhinha/SC
}

D0I: http://dx.doi.org/10.18616/civiltec.v2i1.5334

Jorge Luiz Vieira ${ }^{1}$

Evelise Chemale Zancan²

Vanildo Rodrigues ${ }^{3}$

\section{Introdução}

A interação do meio acadêmico com a comunidade desperta o senso crítico e coloca desafios para a aplicação da criatividade e dos saberes teóricos e práticos adquiridos ao longo da formação universitária nos cursos de arquitetura e urbanismo e de engenharias. Nessa perspectiva, o Escritório Modelo Interdisciplinar de Assistência Técnica (EMI), que integra a estrutura do Programa Permanente de Extensão Habitat + Humano, Inclusivo e Sustentável (PEHIS), da Universidade do Extremo Sul Catarinense (UNESC), trabalha as atividades extensionistas interdisciplinares em parceria com instituições locais. O Estatuto da Cidade estabelece a possibilidade de cooperação entre os governos, a iniciativa privada e os demais setores da sociedade no processo de urbanização, em atendimento ao interesse social das cidades. O EMI tem por objetivo geral propor projetos colaborativos por meio da assistência técnica gratuita, no desenvolvimento de ações que envolvam entidades representativas das comunidades locais, instituições e a administração pública para viabilizar projetos de interesse social no campo da habitação e de equipamentos comunitários. A experiência aqui apresentada compreende a realização de um projeto participativo de urbanização, arquitetura, paisagismo e engenharia de um complexo de equipamentos de cultura, esporte e lazer, sobre uma área de 2,18 ha, localizada no bairro Nova York, com raio de abrangência sobre os bairros Ouro Negro e Vila Franca, situados a leste do centro da cidade de Forquilhinha (SC) e que somam cerca de 1.500 famílias.

\footnotetext{
${ }^{1}$ Doutor, Universidade do Extremo Sul Catarinense, jov@unesc.net

${ }^{2}$ Mestre, Universidade do Extremo Sul Catarinense, ecz@unesc.net

${ }^{3}$ Mestre, Universidade do Extremo Sul Catarinense, vro@unesc.net
} 


\section{Metodologia}

A metodologia do processo do projeto participativo foi baseada em Freire (2013) e adaptada de Imai (2013) por meio de reuniões entre a equipe técnica e a comunidade, seguidas das seguintes etapas: 1) Identificação dos usuários; 2) Identificação das demandas espaciais; 3) Elaboração do programa; 4) Avaliação do partido de projeto por meio de decisões conjuntas entre projetistas e usuários; e 5) Desenvolvimento do projeto por meio de peças gráficas e modelos tridimensionais. A partir das oficinas participativas e das visitas a campo, os acadêmicos e professores dos cursos de arquitetura, engenharia civil e de agrimensura, auxiliados pelas lideranças locais, aplicaram a metodologia de proposição por meio de textos sobre painéis. Nas reuniões com a comunidade, foram aplicados métodos e técnicas de textos curtos em tarjetas expostas em painéis para traduzir as expectativas quanto às atividades e aos espaços para esporte, cultura, recreação e lazer. A exposição dos painéis de proposição de atividades e espaços se deu, inicialmente, em pequenos grupos de até 15 pessoas e, depois, no grande grupo, que reuniu entre 50 e 60 pessoas. Ferramentas de comunicação, na forma de painéis instrutivos, permitiram definir as principais necessidades espaciais elencadas pela equipe, com base nas oficinas, o que gerou o programa e o posterior desenvolvimento do projeto. A participação, ao longo de todo o processo, possibilitou que os usuários, por meio de debate e de reflexão, tivessem clareza e domínio sobre o que efetivamente poderia ser proposto diante da totalidade de suas expectativas.

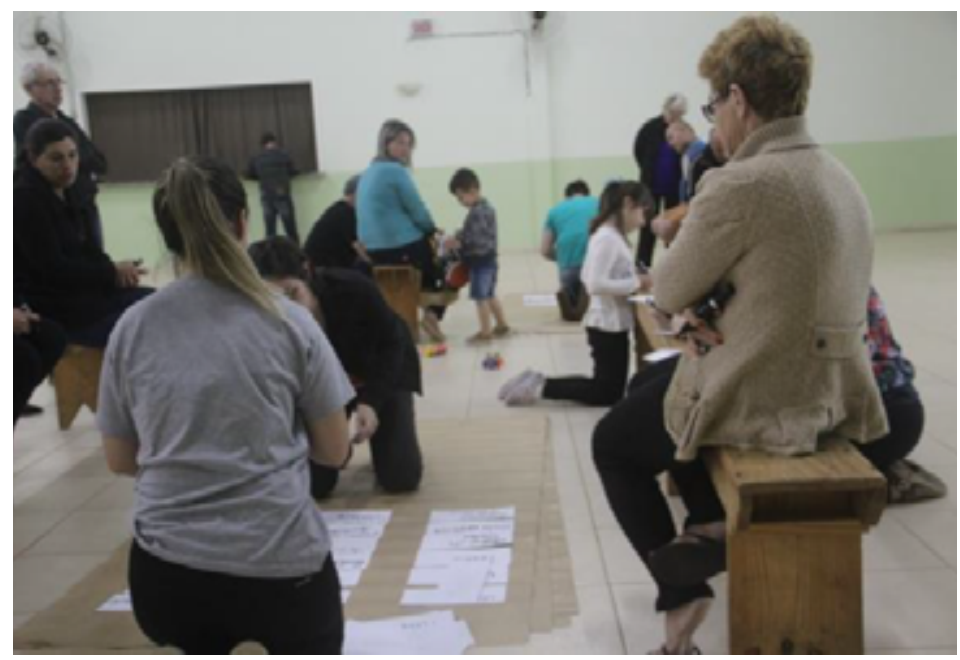

Figura 1 - III Oficina de Projeto Participativo: Painel de Proposição do Programa Fonte: Acervo dos Autores (2018). 


\section{Resultados}

As saídas de campo e o levantamento topográfico planialtimétrico realizados pelo curso de engenharia de agrimensura auxiliaram na confecção da maquete física do recorte e na compreensão da dimensão da área e de sua relação com o entorno. A realização, até o momento, de quatro oficinas com a comunidade permitiu a elaboração do programa de necessidades. Nas duas primeiras oficinas, foram levantados os principais problemas quanto aos espaços para esporte, lazer, recreação e cultura no bairro Nova York e nos bairros vizinhos. As proposições dessas duas oficinas foram sistematizadas pela equipe do projeto para serem votadas na terceira oficina. $\mathrm{Na}$ quarta oficina, foi definido o programa de necessidades para o desenvolvimento do partido, que se encontra em andamento. Paralelamente ao desenvolvimento do partido, os bolsistas realizaram um minucioso levantamento fotográfico da área e do entorno para municiar decisões do projeto quanto à topografia, aos acessos, às áreas de estacionamento, à arborização e à localização dos caminhos, das ciclovias e dos demais equipamentos a serem projetados.

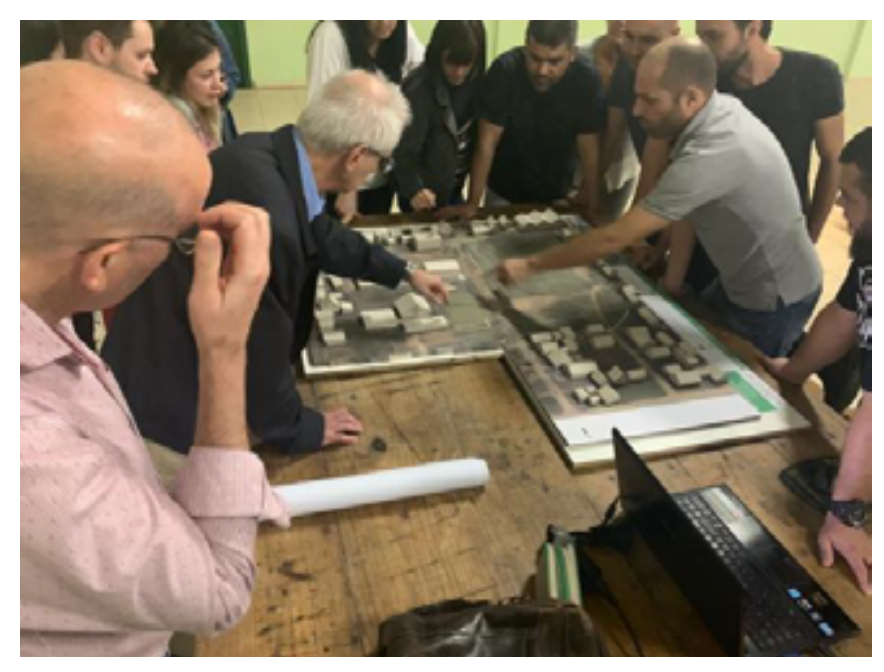

Figura 2 - IV Oficina de Projeto Participativo: Maquete física do recorte

Fonte: Acervo dos Autores (2018).

\section{Conclusões}

Embora o trabalho se encontre em andamento, os resultados até aqui alcançados por meio do processo de projeto participativo têm se mostrado muito acima das expecta- 
tivas, já que houve entendimento por parte da comunidade dos objetivos a serem alcançados em cada oficina de trabalho. A clareza com que a equipe do projeto tem explanado a metodologia, em linguagem acessível às pessoas presentes a cada evento, também contribui para facilitar o andamento do processo. O emprego da maquete física como ferramenta de estudo e de comunicação também auxilia as pessoas a compreenderem o que se está propondo em termos espaciais, que traduzem o programa por elas definido.

Palavras-chave: Projeto de extensão; Projeto participativo; Projeto urbanístico.

Fonte financiadora: PROACAD/UNESC.

\section{Referências}

FREIRE, Paulo. Extensão ou Comunicação? 16. ed. Tradução de Rosiska Darcy de Oliveira. Rio de Janeiro: Paz e Terra, 2013.

IMAI, César. A Participação de Usuários nos Processos Avaliativos: Metodologias e Resultados. In: VILLA, Simone Barbosa; ORNSTEIN, Sheila Walbe (Orgs.). Qualidade ambiental na habitação: avaliação pós-ocupação. São Paulo: Oficina de Textos, 2013, p. 75-91. 